ROMEIRO, B. P.; FRANÇA, J. A. L.; GONÇALVES, W. S.; BENETT, C. G. S. Distribuição de gotas de um pulverizador hidráulico de barras de baixo custo. Revista de Agricultura Neotropical, Cassilândia-MS, v. 2, n. 2, p. 19-25, abr./jun. 2015.

\title{
DISTRIBUIÇÃO DE GOTAS DE UM PULVERIZADOR HIDRÁULICO DE BARRAS DE BAIXO CUSTO
}

\section{BRUNO PERES ROMEIRO ${ }^{1}$, JORGE ALFREDO LUIZ FRANÇA ${ }^{1}$, WAGNER SANTOS GONÇALVES ${ }^{2}$, CLEITON GREDSON SABIN BENETT ${ }^{1}$}

\author{
1 Instituto Federal Goiano, Urutaí-GO, Brasil, brunopromeiro@hotmail.com, jorge.10.franca@gmail.com, \\ cbenett@hotmail.com, ${ }^{2}$ Instituto Federal Goiano, Cristalina-GO, Brasil, wwagnerr@gmail.com
}

RESUMO: Em meio à diversidade de componentes do processo de produção agrícola, destaca-se a tecnologia de aplicação de produtos fitossanitários, que é a responsável pela colocação correta dos produtos no alvo. Assim, objetivou-se nesse trabalho avaliar a uniformidade da distribuição das gotas de pulverização no solo descoberto e na parte superior, média e inferior da planta, utilizando um pulverizador hidráulico de barras de baixo custo, para tratores com baixa demanda de potência e de baixo investimento financeiro. $\mathrm{O}$ trabalho foi conduzido em área experimental do Instituto Federal Goiano - Câmpus Urutaí, na cidade de Urutaí-GO. Foram realizados quatro experimentos para avaliação do número de gotas $\mathrm{cm}^{-2}$, realizados em delineamento inteiramente casualizado, com dois tratamentos: 7 e $11 \mathrm{~km} \mathrm{~h}^{-1} \mathrm{de}$ velocidade de deslocamento com nove repetições. O experimento foi conduzido em área com cultivo de milheto (Pennisetum americanum) e utilizou-se papel hidrossensível fixado às plantas. Para a realização da leitura dos papéis sensíveis à água foi utilizado o software Gotas. Os dados foram submetidos à análise de variância pelo teste $\mathrm{F}$ e as médias comparadas pelo Teste de Tukey. O pulverizador hidráulico proporcionou padrão de densidade de cobertura satisfatória na velocidade de $7 \mathrm{~km} \mathrm{~h}^{-1}$. A velocidade de deslocamento de $11 \mathrm{~km} \mathrm{~h}^{-1}$ proporcionou baixa cobertura das gotas de pulverização.

PALAVRAS-CHAVE: Pulverização, papel hidrossensível, uniformidade de gotas.

\section{DROPS DISTRIBUTION OF A LOW COST HYDRAULIC SPRAYER WITH BARS}

\begin{abstract}
Among the different components of the agricultural production process, there is the pesticide application technology, which is responsible for the correct placement of product on target. Thus, the aim of this study was to evaluate the distribution uniformity of spray droplets on soil and at the upper third, middle and lower of the plants, using a hydraulic bar's sprayer of low cost for tractors with low power demand and low investment. The work was conducted in the experimental area of the Institute Federal Goiano, in Urutaí-GO, Brazil. Four experiments were conducted to evaluate the number of droplets per $\mathrm{cm}^{2}$, conducted in a completely randomized design with two-displacement speed $\left(7\right.$ and $\left.11 \mathrm{~km} \mathrm{~h}^{-1}\right)$ and nine repetitions. The experiment was conducted in a millet-growing area. Water-sensitive paper attached to plants were used. The reading of the number of droplets in the water-sensitive paper was performed using the software Drops ${ }^{\circledR}$. Data were subjected to analysis of variance by $\mathrm{F}$ test, and means were compared by the Tukey test at the 0.05 level of confidence. The hydraulic spray resulted in a satisfactory coverage density in the speed of $7 \mathrm{~km} \mathrm{~h}^{-1}$. The displacement speed of $11 \mathrm{~km} \mathrm{~h}^{-1}$ provided low coverage of spray droplets.
\end{abstract}

KEYWORDS: Spray, water sensitive paper, uniformity of drops per $\mathrm{cm}^{2}$. 


\section{INTRODUÇÃO}

Em meio à diversidade de componentes do processo de produção agrícola, destaca-se a tecnologia de aplicação de produtos fitossanitários que é responsável pela colocação correta dos produtos no alvo. Fazendo uso desta tecnologia observa-se vantagens na preservação da saúde do trabalhador, na conservação do meio ambiente e na rentabilidade da produção.

A utilização de defensivos agrícolas constitui uma prática comum no controle de pragas e doenças na maioria das culturas, representando parte significativa nos custos de produção. Portanto, são de interesse para os agricultores, a máxima efetividade e custos mínimos na aplicação destes produtos (FRANÇA, 2015).

Santos (2005) estabelece uma diferença entre pulverização e aplicação. A pulverização "é um processo físico-mecânico de transformação de uma substância sólida ou liquida em partículas ou gotas tanto mais uniformes e homogêneas quanto possíveis", a aplicação "consiste na deposição em quantidade e qualidade do ingrediente ativo definido, representado pelo diâmetro e densidade (número) de gotas sobre o alvo desejado".

Durante as aplicações o ideal é que o espectro de gotas seja homogêneo, isto é, que se produzam gotas de mesmo tamanho. Deve-se cuidar para que não sejam produzidas gotas muito grossas nem muito finas, evitando-se assim perdas por deriva e escorrimento. É preciso conhecer as características técnicas das pontas, visando à sua correta seleção e, com isso, aplicações eficientes e seguras ambientalmente. Nas pontas de pulverização que operam com pressão hidráulica a formação de gotas, muitas vezes, é bastante desuniforme, dificultando a boa cobertura do alvo (CUNHA et al., 2007).

O volume de aplicação é o maior responsável por resultados não satisfatórios ou abaixo da expectativa em aplicações de produtos fitossanitários para diferentes cultivos (AZEVEDO; FREIRE, 2006). O volume ideal é aquele que gera gotas corretas e adequadas para cada tipo de aplicação, proporciona boa deposição sobre as plantas, excelente penetração dentro do dossel, alta eficiência e minimização de perdas.

Alguns pesquisadores consideram que gotas menores que $100 \mu \mathrm{m}$ são facilmente carregadas pelo vento, sofrendo mais intensamente a ação dos fenômenos climáticos (CUNHA et al., 2004). As pontas de jato cônico vazio produzem, em geral, gotas finas, que apresentam trajetórias tangenciais facilitando assim a penetração das gotas no dossel das plantas (ZHU et al., 2004).

No entanto, quando em uma aplicação as gotas são finas há risco de contaminação ambiental e humana em função da deriva e, por isso, têm-se buscado alternativas que minimizem tais problemas (STAINIERA et al., 2006; NUYTTENS et al., 2007). Uma das alternativas para reduzir esses riscos é a utilização de pontas que produzem gotas de maior tamanho, como as pontas de jato plano duplo com indução de ar. De acordo com Viana et al. (2007), a princípio, gotas extremamente grossas são indicadas para aplicação de herbicidas em pré e pós-emergência e dessecação em condições climáticas desfavoráveis, não devendo ser empregadas quando se requer elevada cobertura do alvo.

A aplicação correta de produtos fitossanitários pode melhorar sua eficácia biológica e reduzir danos causados às culturas vizinhas, ao meio ambiente e ao homem. Essa aplicação é realizada, normalmente, utilizando pulverização hidráulica, que é definida como "processo mecânico de geração de gotas" (CORDEIRO, 2001; MATUO et al., 2001). As gotas são produzidas pelas pontas de pulverização, que também determinam a vazão e a distribuição do 
líquido pulverizado, sendo, portanto, o equipamento mais importante do pulverizador (BAUER; RAETANO, 2004).

Objetivou-se nesse trabalho avaliar a uniformidade na distribuição das gotas $\mathrm{cm}^{-2} \mathrm{em}$ solo descoberto e na parte superior, média e inferior da planta, utilizando um pulverizador hidráulico de barras de baixo custo, para tratores com baixa demanda de potência e de baixo investimento financeiro.

\section{MATERIAL E MÉTODOS}

O trabalho foi conduzido em área experimental do Instituto Federal Goiano - Câmpus Urutaí, na cidade de Urutaí-GO, com altitude média de $821 \mathrm{~m}$ e latitude $17^{\circ} 27^{\prime} 52^{\prime \prime}$ Sul e longitude $48^{\circ} 12^{\prime} 13^{\prime \prime}$ Oeste. Segundo classificação Köppen, o clima é Cwa, caracterizado como úmido tropical com inverno seco e verão chuvoso.

Foi utilizado um pulverizador desenvolvido no Instituto Federal Goiano - Câmpus Urutaí, o qual consta de um chassi metálico retangular, dois tanques de pulverizadores costais com capacidade para $20 \mathrm{~L}$ cada, caixa de redução, conjunto de engrenagens e sistema de manivela biela para acionamento do mecanismo de pressurização dos pulverizadores (Figura $1)$.

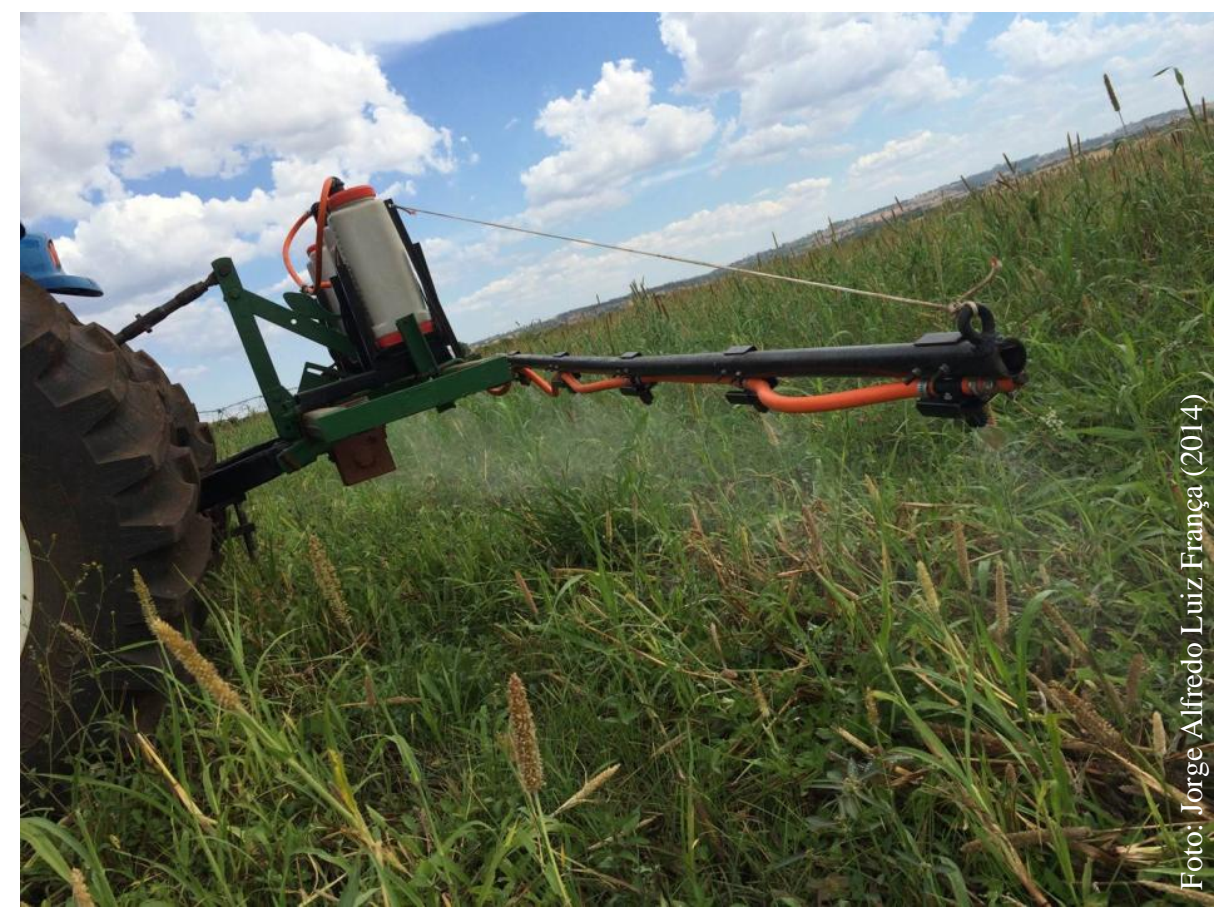

Figura 1: Pulverizador hidráulico de barras de baixo custo em funcionamento.

Foram colocados dois tanques de pulverizadores costais de $20 \mathrm{~L}$ cada, com mecanismo de fixação que permite a retirada dos tanques para limpeza e reparos no cilindro de pressão. $\mathrm{O}$ mecanismo de suporte do reservatório de líquido foi desenvolvido de modo a ser leve e prático para que a manutenção da máquina seja possível de ser efetuada por apenas um operador. Como a máquina é destinada para uso em pequenas áreas, não foi necessário o uso de tanques de reservatório de líquido de grandes capacidades.

O comprimento total das barras de pulverização foi de seis metros e foram divididas em três secções, de modo que a secção central fica fixa ao chassi e as secções laterais são colocadas na posição vertical nos momentos de transporte, quando a máquina não é utilizada. As barras de pulverização possuem perfil cilíndrico com mecanismo de suporte dos bicos de 
pulverização a cada $0,5 \mathrm{~m}$ e contém 12 pontas de pulverização. As barras são leves, minimizando a necessidade de sistema de amortecimento sem comprometer a estabilidade e causar danos às barras em terrenos irregulares.

O sistema de bombeamento da calda foi feito a partir da potência disponível na tomada de potência do trator. A tomada de potência aciona uma caixa de redução acoplada ao chassi, que aciona um eixo com uma corrente, a qual aciona engrenagens acopladas a um eixo que possui sistema de manivela biela em cada uma das duas extremidades. Este sistema manivela biela transforma o movimento circular fornecido pela tomada de potência do trator em movimento do tipo alternado para acionamento dos tanques de pulverizadores costais. Os tanques de pulverização são acionados por movimentos alternados do braço do operador. Com esta adaptação do sistema de acionamento dos tanques por meio do sistema manivela biela foi possível simular o movimento do tipo alternado para realizar o acionamento dos tanques de pulverização.

Foram utilizadas mangueiras de pulverização de meia polegada de diâmetro, um manômetro analógico com glicerina instalado entre os tanques dos pulverizadores e bicos de pulverização; para medição da densidade de gotas $\mathrm{cm}^{-2}$ foram utilizadas pontas de pulverização tipo "leque" da marca Magno Jet, série TP cor azul, número 03, com ângulo de $110^{\circ}$, construídas em poliacetal, com filtro de malha 50 e com vazão de $1,0 \mathrm{~L} \mathrm{~min}^{-1}$ (com pressão de $207 \mathrm{kPa}$ ) a 1,43 $\mathrm{L} \mathrm{min}^{-1}$ (com pressão de $414 \mathrm{kPa}$ ) (MAGNO JET, 2014). Para transporte e acionamento dos pulverizadores foi utilizado um trator marca comercial LS Tractor, modelo Plus de $88 \mathrm{cv}$. Durante o experimento a temperatura ambiente foi de $28^{\circ} \mathrm{C}$, velocidade do vento de $8 \mathrm{~km} \mathrm{~h}^{-1}$ e umidade relativa do ar de $33 \%$, segundo informações coletadas na estação meteorológica do Instituto Federal Goiano - Câmpus Urutaí.

Foram realizados quatro experimentos: o primeiro para avaliação do número de gotas $\mathrm{cm}^{-2}$ no terço inferior da planta, realizado em delineamento inteiramente casualizado, com dois tratamentos: 7 e $11 \mathrm{~km} \mathrm{~h}^{-1}$ de velocidade de deslocamento com nove repetições. $\mathrm{O}$ segundo experimento para avaliação do número de gotas $\mathrm{cm}^{-2}$ no terço médio da planta, realizado em delineamento inteiramente casualizado, com dois tratamentos: 7 e $11 \mathrm{~km} \mathrm{~h}^{-1}$ de velocidade de deslocamento com nove repetições. O terceiro para avaliação do número de gotas $\mathrm{cm}^{-2}$ no terço superior da planta, realizado em delineamento inteiramente casualizado, com dois tratamentos: 7 e $11 \mathrm{~km} \mathrm{~h}^{-1}$ de velocidade de deslocamento com nove repetições. $\mathrm{O}$ quarto experimento para avaliação do número de gotas $\mathrm{cm}^{-2}$ depositadas no solo, realizado em

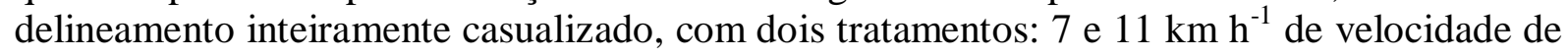
deslocamento com nove repetições.

A pressão de serviço foi de $211 \mathrm{Kpa}$. A área utilizada para avaliar o número de gotas $\mathrm{cm}^{-2} \mathrm{em}$ cada velocidade foi de $6 \mathrm{~m}$ de largura (largura das barras de pulverização) x $5 \mathrm{~m}$ de comprimento, totalizando $30 \mathrm{~m}^{2}$. As etiquetas de papéis hidrossensíveis foram espalhadas dentro dessa área, e em cada planta sorteada aleatoriamente foram colocados nos três terços da mesma. Cada papel hidrossensível com medidas de 26 x $76 \mathrm{~mm}$ considerado como uma repetição. Na ocasião dos experimentos as plantas de sorgo apresentavam altura em torno de $60 \mathrm{~cm}$, com isso cada terço onde foram dispostos os papéis hidrossensíveis foi constituído de partes de $20 \mathrm{~cm}$.

Cada experimento constou da avaliação dos papéis hidrossensíveis em cada terço da planta (inferior, médio e superior) e solo. Com isso, o fato de ser DIC e não DBC, foi devido à escolha aleatória das plantas e dos locais do solo onde foram dispostos os papéis hidrossensíveis. As condições meteorológicas e de solo foram homogêneas durante a realização do experimento (parcela relativamente pequena e passadas consecutivas do trator) 


\section{RESULTADOS E DISCUSSÃO}

O pulverizador apresentou resistência mecânica satisfatória durante a realização do experimento, antes da avalição principal o mesmo foi submetido a uma avaliação teste para avaliar sua resistência. $\mathrm{O}$ sistema de manivela biela proporcionou o acionamento dos tanques dos pulverizadores de forma suave e uniforme.

Com a análise de variância da densidade de gotas $\mathrm{cm}^{-2}$ verificou-se significância do tratamento velocidade de deslocamento do conjunto mecanizado na aplicação no terço inferior, terço superior e no solo sem cobertura. Na análise de variância do terço médio não ocorreu significância do tratamento aplicado. As médias das densidades de gotas obtidas nas avaliações estão apresentadas na Tabela 1.

Tabela 1. Valores médios obtidos para densidade de gotas $\mathrm{cm}^{-2}$ em função da velocidade de deslocamento no terço inferior, médio, superior e em solo.

\begin{tabular}{ccccc}
\hline \multicolumn{5}{c}{ Terços da planta } \\
\hline Velocidade & Terço inferior & Terço médio & Terço superior & Solo \\
\hline $7 \mathrm{~km} \mathrm{~h}^{-1}$ & $20,40 \mathrm{a}$ & $17,94 \mathrm{a}$ & $23,05 \mathrm{a}$ & $23,29 \mathrm{a}$ \\
$11 \mathrm{~km} \mathrm{~h}^{-1}$ & $15,52 \mathrm{~b}$ & $11,76 \mathrm{a}$ & $14,92 \mathrm{~b}$ & $14,76 \mathrm{~b}$ \\
\hline C.V. $(\%)$ & 23,57 & 46,67 & 39,39 & 28,24 \\
\hline
\end{tabular}

Médias seguidas pelas mesmas letras nas colunas são estatisticamente iguais pelo teste de Tukey ao nível de 5\% de probabilidade. C. V.(\%): Coeficiente de variação.

Volpe et al. (2012) sugeriram que, para experimentos desenvolvidos em condições de laboratório, os coeficientes de variação aceitáveis devem ser até $10 \%$, visto que, em aplicações realizadas em campo, o valor do coeficiente de variação tende a aumentar, devido as condições climáticas inerentes por ocasião da aplicação e/ou movimentos desordenados da barra de pulverização ocasionados pelo deslocamento do trator sobre o solo.

Apesar dos altos valores de C.V. obtidos neste experimento, os resultados estão de acordo com os obtidos por Berni et al. (1999); C.V. de 33,99\% em experimento na cultura do feijão avaliando média de cobertura $\left(\right.$ gotas $\mathrm{cm}^{-2}$ ) obtidos de quatro bicos de pulverização, na linha e na entrelinha e em três alturas de coleta (dossel, mediana e nível do solo), recolhidos em papel hidrossensível, e C.V. de $29,64 \%$ na cultura do milho. Román et al. (2009) avaliando a cobertura da calda de fungicida na cultura da soja com dois tipos de ponta de pulverização e três volumes de calda de pulverização $\left(100,150\right.$ e $\left.200 \mathrm{~L} \mathrm{ha}^{-1}\right)$ com papel hidrossensível, encontraram os valores de C.V. de 79,07\% no terço inferior, $103,93 \%$ no terço médio e $66,82 \%$ no terço superior das plantas.

O pulverizador foi regulado para aplicação de herbicidas conforme normas da ANDEF (2004) onde rege que a pulverização de herbicidas, quando avaliada no parâmetro de densidade de cobertura (gotas $/ \mathrm{cm}^{2}$ ), deve apresentar de 20 a 30 gotas $\mathrm{cm}^{-2}$.

O pulverizador hidráulico proporcionou padrão de densidade de cobertura satisfatória na velocidade de $7 \mathrm{~km} \mathrm{~h}^{-1}$ nos terços inferior, superior e no solo. Apesar de se aproximar do valor recomendado no terço médio não obteve o resultado recomendado na velocidade de7 $\mathrm{km} \mathrm{h}^{-1}$.

\section{CONCLUSÃO}

Menores velocidades de deslocamento do trator proporcionam melhores resultados no padrão de densidade de cobertura. 


\section{REFERÊNCIAS BIBLIOGRÁFICAS}

ANDEF. ASSOCIAÇÃO NACIONAL DE DEFESA VEGETAL. Manual de Tecnologia de Aplicação de Produtos Fitossanitários. São Paulo-SP: Linea Creativa, 2004.

AZEVEDO, F. R.; FREIRE, F. C. O. Tecnologia de aplicação de defensivos agrícolas. Fortaleza-CE: Embrapa Agroindustrial Tropical, 2006. 47 p. (Documentos, 102). Disponível em: <http://www.uenf.br/Uenf/Downloads/PRODVEGETAL_3434 1345744500.pdf> Acesso em: 7 maio 2015.

BAUER, F. C.; RAETANO, C. G. Distribuição volumétrica de calda produzida pelas pontas de pulverização XR, TP e TJ sob diferentes condições operacionais. Planta Daninha, ViçosaMG, v. 22, n. 2, p. 275-284, 2004.

BERNI, R. F.; MACHADO, V. O. F.; COSTA, G. R.; BARATA, G.; PAULA, R. S. Avaliação da cobertura de gotas provocada por diferentes bicos de pulverização na cultura do milho e do feijão. Pesquisa Agropecuária Tropical, Goiânia-GO, v. 29, n. 1, p. 49-52, 1999.

CORDEIRO, A. M. C. Como a tecnologia de aplicação de produtos fitossanitários pode contribuir para o controle de pragas, doenças e plantas daninhas. In: ZAMBOLIM, L. Manejo integrado: fitossanidade, cultivo protegido, pivô central e plantio direto. Viçosa-MG: UFV, 2001. p. 683-721.

CUNHA, J. P. A. R.; TEIXEIRA, M. M.; FERNANDES, H. C. Avaliação do espectro de gotas de pontas de pulverização hidráulica utilizando a técnica da difração do raio laser. Engenharia Agrícola, Jaboticabal-SP, v. 27, número especial, p. 10-15, 2007. Disponível em: <http://www.scielo.br/scielo.php?pid=S0100-69162013000500009\&script=sci_arttext $>$. Acesso em: 8 mar. 2015.

CUNHA, J. P. A. R.; TEIXEIRA, M. M.; VIEIRA, R. F.; FERNANDES, H. C.; COURY, J. R. Espectro de gotas de bicos de pulverização hidráulicos de jato plano e de jato cônico vazio. Pesquisa Agropecuária Brasileira, Brasília-DF, v. 39, n. 10, p. 977-985, 2004. Disponível em: <http://www.scielo.br/scielo.php?pid=S0100-69162013000500009\&script=sci_arttext $>$. Acesso em: 8 mar. 2015.

FRANÇA, J. A. L.; GONÇALVES, W. S.; ROMEIRO, B. P.; BENETT, C. G. S.; SILVA, A. R. Desenvolvimento e avaliação de um pulverizador hidráulico de barras rígidas horizontais de baixo custo. Revista de Agricultura Neotropical, Cassilândia-MS, v. 2, n. 1, p. 17-23, 2015.

MAGNO JET, 2014. Disponível em: http://www.magnojet.com.br/magnojet/pt/produtos.php?Catalogo=detalhar_produto\&idProdu to=141\&nomeProd=bico_leque_serie_tp\&TipoMidiaProduto=Imagem. Acesso em: 15 mar. 2015.

MATUO, T.; PIO, L. C; RAMOS, H. H.; FERREIRA, L. R. Tecnologia de aplicação e equipamentos. In: ABEAS. Curso de proteção de plantas. Viçosa-MG: UFV, 2001. 85 p. (Módulo 2. Brasília, DF, ABEAS.). Disponível em: <http://www.scielo.br/scielo.php?script=sci_arttext\&pid=S0100-83582005000100019>. Acesso em: 10 mar.2015.

NUYTTENS, D.; BAETENS, K.; DE SCHAMPHELEIRE, M.; SONCK, B. Effect of nozzle type, size and pressure on spray droplet characteristics. Biosystems Engineering, Silsoe, v. 97, n. 3, p. 333-345, 2007. Disponível em: <http://www.scielo.br/scielo.php?pid=S010069162013000500009\&script=sci_arttext $>$. Acesso em: 10 de março de 2015. 
ROMÁN, R. A. A.; CORTEZ, J. W.; FERREIRA, M. C.; OLIVEIRA, J. R. G. Cobertura da cultura da soja pela calda fungicida em função de pontas de pulverização e volumes de aplicação. Scientia Agraria, Curitiba-PR, v. 10, n. 3, p. 223-232, 2009.

SANTOS, J. M. F. Tecnologia de aplicação de defensivos agrícolas. São Paulo-SP: Instituto Biológico, Centro de Pesquisa e Desenvolvimento de Sanidade. 2005. Disponível em: <http://www.biologico.sp.gov.br>. Acesso em: 12 mar. 2015.

STAINIERA, C.; DESTAINA, M.F.; SCHIFFERSB, B.; LEBEAUA, F. Droplet size spectra and drift effect of two phenmedipham formulations and four adjuvants mixtures. Crop Protection, London, v. 25, n. 12, p. 1.238-1.243, 2006. Disponível em: <http://www.scielo.br/scielo.php?pid=S0100-69162013000500009\&script=sci_arttext . Acesso em: 12 mar. 2015.

VIANA, R.G.; FERREIRA, L.R.; TEIXEIRA, M.M.; CECON, P.R.; FREITAS, F.C.L.; QUIRINO, A.L.S.; SANTOS, M.V. Características técnicas de pontas de pulverização LA1JC e SR-1. Planta Daninha, Viçosa-MG, v. 25, n. 1, p. 211-218, 2007. Disponível em: <http://www.scielo.br/scielo.php?pid=S0100-69162013000500009\&script=sci_arttext>.

Acesso em: 5 mar. 2015.

VOLPE, H. X. L.; DUARTE, R. T.; SILVA, A. G.; BALDAN JÚNIOR, E.; LEITE, G. J.; FERREIRA, M. da C. Distribuição volumétrica de calda contendo Metarhizium anisopliae, Ciência Rural, Santa Maria-RS, v. 42, n. 11, 2012. Disponível em: <http://www.scielo.br/scielo.php?pid=S010384782012001100001\&script=sci_arttext\&tl>. Acesso em: 9 mar. 2015.

ZHU, L. D.; WANG, C. S.; LIU, H. S.; XIANG, D. Z.; Liu, F., ZHAO, Z. F.; LIU, X. X. Basin system evolution and formation time of Qinghai-Tibet Plateau. Journal of Chengdu University of Technology (Science and Technology Edition), China, v. 31, n. 3, p. 249-255, 2004. (in Chinese, with English Abstr.). Disponível em: <http://www.scielo.br/scielo.php?pid=S010069162013000500009\&script=sci_arttext >. Acesso em: 6 mar. 2015. 